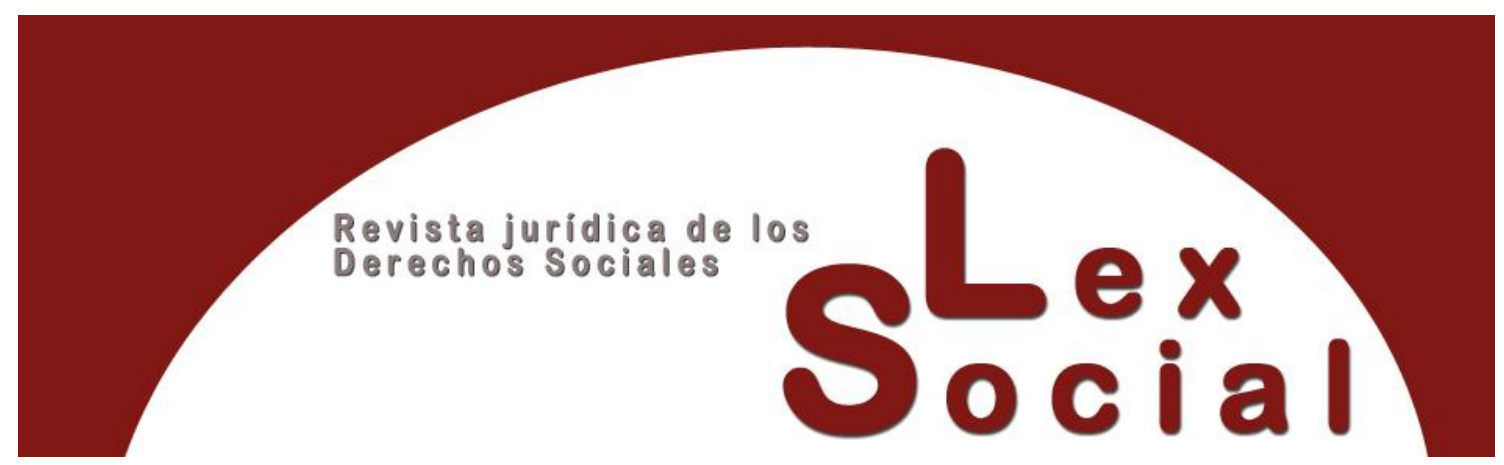

\title{
PRECARIEDAD DEL TRABAJO RETRIBUIDO DE CUIDADOS: ORIGEN Y MECANISMOS DE SOLUCIÓN ${ }^{1}$
}

\section{PRECARIOUSNESS OF PAID CARE WORK: ORIGINS AND MECHANISMS OF SOLUTION}

\author{
HENAR ÁLVAREZ CUESTA \\ Profesora Titular de Derecho del Trabajo y de la Seguridad Social \\ Universidad de León \\ http://orcid.org/0000-0003-0957-1515
}

\begin{abstract}
Cómo citar este trabajo: Álvarez Cuesta, H. (2021). Precariedad del trabajo retribuido de cuidados: origen y mecanismos de solución. Lex Social: Revista De Derechos Sociales, 11 (2), 570-593. https://doi.org/10.46661/lexsocial.5961
\end{abstract}

\section{RESUMEN}

El sector de los cuidados retribuidos ha sido un nicho de empleo desde su origen para las mujeres y, como característica añadida (consecuencia y causa recíproca), ha merecido el calificativo de precario. El presente estudio analiza las distintas ocupaciones (feminizadas y precarias) más significativas asociadas a este ámbito, como las auxiliares de ayuda a domicilio, las cuidadoras en residencias o no profesionales de dependientes, las limpiadoras o las empleadas de hogar. A continuación, examina sus rasgos característicos y regulación para poner de relieve sus causas de temporalidad, parcialidad, bajos salarios o malas condiciones laboral. Por último, propone las soluciones legales y/o convencionales oportunas en cada caso para poner freno y fin a esa situación y unir la calificación de esenciales y dignos a estos trabajos feminizados.

Palabras Clave: precariedad, cuidados, igualdad, temporalidad, parcialidad.

\footnotetext{
${ }^{1}$ Investigación realizada en el marco del Proyecto de Investigación LE013P20 de la Junta de Castilla y León "La prestación de servicios socio-sanitarios en el ámbito rural de Castilla y León: apostando por un bienestar integral".
}

\section{(cc) BY-NC-SA}




\begin{abstract}
The paid care sector has been an employment opportunity for women since its inception and, as an added characteristic (a consequence and reciprocal cause), it has been labelled as precarious. This study analyses the most significant occupations (feminised and precarious) associated with this field, such as home helpers, residential or non-professional carers of dependents, cleaners and domestic workers. Then it examines their characteristic features and regulations in order to highlight the causes of their temporary, partial, low pay and poor working conditions. Finally, it proposes the appropriate legal and/or conventional solutions in each case in order to put an end to this situation and to unite the qualification of these feminised jobs as essential and dignified.
\end{abstract}

KEYWORDS: precariousness, care, equality, temporariness, part-time work, part-time work.

SUMARIO

I. Sectores de cuidados feminizados y esenciales.

1. Cuidadoras no profesionales con dedicación permanente.

2. Cuidadoras en residencias de atención a la tercera edad y ayuda a domicilio.

3. Limpiadoras y "kellys" entre la subcontratación y las empresas multiservicios.

4. Las siempre invisibles empleadas de hogar

II. La precariedad unida a las condiciones de trabajo en el sector cuidados.

III. El trabajo decente como antídoto de la precariedad.

1. La ley como motor de cambio.

2. Buenas prácticas convencionales

3. Valoración de los trabajos de cuidados como esenciales e imprescindibles

Bibliografía

Anexo

"Eses manes sabies de mio güela que ficieron caldiu l'inviernu texiendo mantes meyores que les de cualquier Penélope, que tornaben la pena en risa sólo con dexame la caxa botones pa xugar. Eses manes".

[Esas manos sabias de mi abuela/ que hicieron cálido el invierno tejiendo/ mantas mejores que las de cualquier/ Penélope, que convertían la tristeza en risa/ solo con dejarme la caja de botones/ para jugar./ Esas manos]. Sofía Castañón. Agora escuende les manes. Las cañas pretenciosas. 


\section{Sectores de cuidados feminizados y esenciales}

Los cuidados son un concepto pluridimensional que comprende diversas actividades y en el cual resulta complejo establecer límites ${ }^{2}$, pero si hay un rasgo común a todos ellos es aquel que define quién los asume (incluyendo los remunerados y los no remunerados): las mujeres. Los datos respaldan la afirmación precedente: "la fuerza de trabajo mundial dedicada a la prestación de cuidados asciende a 381 millones de trabajadores: 249 millones de mujeres y 132 millones de hombres. Estas cifras representan el 11,5 por ciento del empleo mundial total, el 19,3 por ciento del empleo femenino mundial y el 6,6 por ciento del empleo masculino mundial"3. En Europa, el 90\% de personas trabajadoras en el sector cuidados en 2019 eran mujeres ${ }^{4}$.

La otra característica que califica la actividad desempeñada (y no quienes la realizan) es la precariedad y unida a ella como causa-efecto bidireccional, la falta de reconocimiento social y de valoración de su actividad", la cual constituye una "realidad inevitable en un contexto sociodemográfico y socioeconómico muy preciso"6. Quizá, a raíz de la declaración del estado de alarma en virtud del RD 463/2020, de 14 de marzo, derivado de la pandemia causada por la Covid19 y del RD-Ley 10/2020, de 29 de marzo, por el que se regula un permiso retribuido recuperable para las personas trabajadoras por cuenta ajena que no presten servicios esenciales, parecen mejor acotadas cuáles son las ocupaciones necesarias, entre las que figura el trabajo de cuidados. Su calificación como esencial ha de ir anudada, en consecuencia, con el fortalecimiento de estas actividades y el aseguramiento de unas condiciones de trabajo dignas en aras a proteger a la sociedad en su conjunto ${ }^{7}$.

Hasta ahora, las cuidadoras han asumido tradicionalmente todo un conjunto de obligaciones y responsabilidades que han condicionado su propio proyecto vital, llegando incluso a neutralizarlo. Pese a constituir una actividad esencial para el bienestar personal y tener un impacto de primer orden en el cuidador y en la persona cuidada, el Derecho del Trabajo ha silenciado su reconocimiento y su dignificación ${ }^{8}$.

En España este sector tiene unos rasgos propios, fruto de la propia composición cultural y social del país, entre los que destaca el peso elevadísimo de la familia, un protagonismo

\footnotetext{
${ }^{2}$ MOLERO MARAÑÓN, Ma Luisa, "Las trabajadoras del cuidado: por un futuro del trabajo decente", Revista de Derecho Social, $\mathrm{n}^{\circ} .89,2020$, p. 35.

${ }^{3}$ OIT, El trabajo de cuidados y los trabajadores del cuidado para un futuro con trabajo decente. Ginebra: OIT, 2018, p. 14.

${ }^{4}$ BUCKINGHAM, Sophie et alii: Precarious work from a gender and intersectionality perspective, and ways to combat it. European Unión, 202, p. 48.

5 TOBIO SOLER, C., "Conciliación, cuidado e igualdad de género", en Especialista en gestión de políticas de igualdad, Thomson Aranzadi, 2019, p. 156.

${ }^{6}$ QUINTERO LIMA, Ma . Gema, "El trabajo de servicio domestico como una realidad jurídica inevitable", Revista Lex Social: Revista de Derechos Sociales, no. 2, 2019, p. 4.

7 ÁLVAREZ CUESTA, Henar, "El futuro del trabajo después de la pandemia y los empleos del futuro", Gaceta Sindical, n. 35, 2020, p. 173.

${ }^{8}$ MOLERO MARAÑÓN, Ma Luisa, "Las trabajadoras del cuidado: por un futuro del trabajo decente", cit., p. 39.
} 
indiscutible del sector doméstico y la presencia clave de mujeres inmigrantes dentro de la economía del cuidado9.

Frente a las coordenadas apuntadas, conviene realizar un breve recorrido por las características de las prestaciones de servicios retribuidos de algunas de las actividades más representativas del sector analizado, como son las realizadas por las cuidadoras no profesionales, las cuidadoras en residencias y de ayuda a domicilio, las limpiadoras y camareras de hoteles y las empleadas de hogar.

\section{Cuidadoras no profesionales con dedicación permanente}

Este primer grupo, el de las cuidadoras no profesionales, constituye un colectivo a medio camino entre la visibilización del trabajo retribuido y la ocultación del trabajo de cuidados. Realizan su actividad dentro del marco de la Ley 39/2006, de 14 de diciembre, de Promoción de la Autonomía Personal y Atención a las personas en situación de dependencia, y para unos beneficiarios cada vez más numerosos, no en vano hasta el año 2019 el número de personas dependientes reconocidas era de 1.385.037, lo que supone que un 3\% de la población necesita algún tipo de apoyo para realizar las actividades básicas del día a día ${ }^{10}$.

A la luz de las cifras anteriores, es fácil constatar cómo la necesidad de cuidados no deja de aumentar, y viene siendo paliada por el sacrificio, en su mayor parte, de las mujeres en el ámbito familiar", bien sea por "hábito" o "costumbre"12. Así, las mujeres que prestan cuidados no profesionales con cargo a la Ley de Dependencia representan el $89 \%{ }^{13}$ siendo las hijas, las madres o las parejas quienes se encargan de esta ardua labor de cuidado ${ }^{14}$ como cuidadoras no profesionales.

Esta figura, contemplada en el art. 18 de la Ley de Dependencia, reconoce una prestación económica a la persona dependiente cuando esté siendo atendida por sujetos de su entorno familiar, siempre que se den condiciones adecuadas de convivencia y de habitabilidad de la vivienda y así lo establezca el programa individual de atención (art. 14.4). De esta forma, el beneficiario de la prestación económica es el propio dependiente, no la cuidadora, sin que se exija que se destine específicamente a remunerar dicha labor, sino que su finalidad es contribuir a aliviar la situación económica de la unidad familiar y

\footnotetext{
${ }^{9}$ MOLERO MARAÑÓN, Ma Luisa, "Las trabajadoras del cuidado: por un futuro del trabajo decente", cit., p. 38.

10 Según los sato del OBSERVATORIO ESTATAL DE LA DEPENDENCIA, XX Dictamen del Observatorio, Madrid (Asociación Estatal de Directoras y Gerentes en Servicios Sociales), 2020, p. 2 https://dependencia.info/imagenes/xx-dictamen-observatorio-dependencia.pdf.

${ }^{11}$ ORDÓÑEZ PASCUA, Natalia y GONZÁLEZ VIDALES, Cristina, "Los vacíos públicos y privados para asumir la tarea de cuidados familiares. la difícil conciliación en el mundo rural. economía social", en $L a$ economía social como palanca para la sostenibilidad en los territorios rurales. Valencia: Tirant lo Blanch, 2021, pp. 212 y ss.

${ }^{12}$ OBSERVATORIO ESTATAL DE LA DEPENDENCIA, XX Dictamen del Observatorio, cit., pág. 31.

13 IMSERSO, Datos sobre cuidadores no profesionales a 31 de diciembre de 2020, 2020, https://www.imserso.es/imserso_01/documentacion/estadisticas/info_d/estadisticas/est_inf/datos_estadisti cos saad/index.htm.

14 OBSERVATORIO ESTATAL DE LA DEPENDENCIA: XX Dictamen del Observatorio, Madrid (Asociación Estatal de Directoras y Gerentes en Servicios Sociales), cit., p. 31.
} 
suplir la pérdida de ingresos provocada por tener que permanecer fuera del mercado laboral ${ }^{15}$.

Aun cuando recibe la cuantía económica, no cabe calificar a la persona dependiente como empleador, ya que la labor del cuidador no está bajo su dirección y supervisión y no asume la obligación de contratación, alta o cotización a la Seguridad Social. Tampoco debe cumplir la normativa de seguridad e higiene en el trabajo, derivada del vínculo laboral, puesto que no existe una relación contractual entre dependiente y cuidador, y el régimen jurídico que regula la figura se encuentra en la norma específica de dependencia y no en el $\mathrm{ET}^{16}$. Por ello, tampoco tienen regulados (ni el derecho a) descansos, vacaciones, permisos o medidas de conciliación entre su vida familiar, personal y laboral, que se superponen hasta hacer desaparecer esta última.

No cabe olvidar que hay un sesgo de género imposible de obviar, ya que alrededor del 93 por 100 de las beneficiarias de las prestaciones por cuidados familiares son mujeres que, por medio de esta medida, han logrado "cierta" (y escasa) visibilización y reconocimiento de un trabajo arduo y penoso, realizado en el interior del hogar, con grandes costes físicos y psicológicos, pero sin obtener un nivel de rentas suficiente, quedando excluidas de la población activa y sin ningún tipo de reconocimiento social ${ }^{17}$.

Se trata de un trabajo "sin derechos", marginado, hasta el momento, de la normativa laboral ${ }^{18}$, para el cual la Resolución de 4 de febrero de 2010, de la Secretaría General de Política Social y Consumo exige que no exista ningún tipo de relación contractual, ni laboral ni de otra clase, tanto si el cuidador es un familiar de la persona dependiente como si es una persona de su entorno ${ }^{19}$.

En muchos casos, estas mujeres, después de muchos años dedicadas a atender a una persona dependiente, al cesar en esta tarea, se encontraban sin la posibilidad de ingresar en un trabajo, fuera por cuenta ajena o propia, en tanto no contaban con experiencia profesional alguna y tampoco podían acreditar tiempo cotizado suficiente para acceder a una prestación contributiva ${ }^{20}$.

Para paliar (que no remediar) esta falta de protección social, y pese a los vaivenes legales, el RD-Ley 6/2019, de 1 de marzo, de medidas urgentes para garantía de la igualdad de

\footnotetext{
15 SELMA PENALVA, Alejandra y LUJÁN ALCARAZ, José, "La reforma del régimen especial de la Seguridad Social de los trabajadores empleados de hogar", Foro de Seguridad Social, n’. 20, 2008, pp. 113114.

${ }^{16}$ GIL PÉREZ, María Encarnación: “Cuidadores o profesionales y derecho a la incapacidad permanente. Problemas que se plantean", Revista de Derecho Social, nº 64, 2013, p. 112.

${ }^{17}$ ESCUDERO RODRÍGUEZ, Ricardo, "Empleo en el sector de la dependencia”, Documentación Laboral, $\mathrm{n}^{\circ} .102,2014$, p. 62.

${ }^{18}$ RODRÍGUEZ ESCANCIANO, Susana, "Dificultades de los servicios sociales en las zonas rurales con especial atención a las personas de edad avanzada", en La economía social como palanca para la sostenibilidad en los territorios rurales. Valencia: Tirant lo Blanch, 2021, pp. 155 y ss.

${ }^{19}$ CORDERO GORDILLO, Vanesa, La relación laboral especial del servicio del hogar familiar. Real Decreto 1620/2011, de 14 de noviembre. Valencia: Tirant lo Blanch, 2014, p. 25.

${ }^{20}$ RODRÍGUEZ ESCANCIANO, Susana y ÁLVAREZ CUESTA, Henar, Trabajo autónomo y trabajo por cuenta ajena: nuevas formas de precariedad laboral. Albacete: Bomarzo, 2019.
} 
trato y de oportunidades entre mujeres y hombres en el empleo y la ocupación, da nueva redacción a la disposición adicional $14^{\mathrm{a}}$ LGSS y recupera en su integridad el convenio especial previsto en el RD 615/2007 por el que se regula la Seguridad Social de los cuidadores de las personas en situación de dependencia (a su vez, la disposición final $2^{\mathrm{a}} .3$ del RD-Ley 8/2019 de 8 de marzo modifica la disposición transitoria $31^{\text {a }}$ LGSS).

\section{Cuidadoras en residencias de atención a la tercera edad y ayuda a domicilio.}

Las prestaciones de servicios proporcionadas en residencias o la ayuda a domicilio están incluidas en el ámbito funcional (art. 1) del VII Convenio marco estatal de servicios de atención a las personas dependientes y desarrollo de la promoción de la autonomía personal $^{21}$. En este punto, y dentro del elenco de trabajos necesarios para proporcionar una atención de calidad a los usuarios de estos servicios, merece centrar la atención en quienes prestan la ayuda de forma más directa, continua y, de nuevo, esencial: aquellas personas que están en el día a día atendiendo y cuidando a las personas de mayor edad.

De acudir a la clasificación profesional prevista en el convenio mencionado, dentro de la división por los correspondientes grupos, estos oficios mencionados aparecen en el nivel más bajo (lo que conlleva una base salarial inferior). Así, dentro del Grupo 4 del citado acuerdo está clasificado el personal auxiliar y los gerocultores (“es el personal que, bajo la dependencia de la dirección del centro o persona que se determine, tiene como función principal la de asistir y cuidar a las personas usuarias en las actividades de la vida diaria que no puedan realizar por si mismos y efectuar aquellas realizaciones profesionales encaminadas a su atención personal y de su entorno"22) y el auxiliar SAD ("es el personal

\footnotetext{
${ }^{21}$ Resolución de 11 de septiembre de 2018, de la Dirección General de Trabajo, por la que se registra y publica el VII Convenio colectivo marco estatal de servicios de atención a las personas dependientes y desarrollo de la promoción de la autonomía personal (residencias privadas de personas mayores y del servicio de ayuda a domicilio), BOE núm. 229, de 21 de septiembre de 2018.

22 "Desarrollará las funciones que se detallan a continuación así como aquellas que le sean solicitadas y que tengan relación con las mismas y/o con su titulación, habilitación o competencia profesional de acuerdo con los protocolos establecidos.

- Apoyar al equipo interdisciplinar en la recepción y acogida de las nuevas personas usuarias colaborando en la adecuación del plan de cuidados individualizado.

- Realizar intervenciones programadas por el equipo interdisciplinar dirigidas a cubrir las actividades de la vida diaria.

- Colaborar en la planificación, organización y ejecución de las actividades preventivas, ocupacionales y de ocio.

- Mantener la higiene personal de las personas usuarias.

- Realizar la limpieza del botiquín y su contenido, así como del resto de material de índole sanitario o asistencial.

- Proporcionar y administrar los alimentos al residente facilitando la ingesta en aquellos casos que así lo requieran.

- Ocuparse de la recepción, distribución y recogida de los alimentos en la habitación de la persona usuaria.

- Realizar los cambios de postura y aquellos servicios auxiliares que de acuerdo con su preparación técnica le sean encomendados.

- Colaborar con el servicio de enfermería en la realización de los cambios posturales de las personad encamadas y en las actuaciones que faciliten su exploración y observación.

- Colaborar con el residente en su preparación para un traslado, efectuando actuaciones de acompañamiento, vigilancia y apoyo.

- Colaborar con el personal sanitario en la administración de la medicación.
} 
que tiene por objeto atender, en el propio domicilio o entorno, y siguiendo las pautas de actuación y cuidados indicados por la Coordinación del Servicio"23). En el último, en el

- Colaborar bajo la supervisión de la enfermera en el cuidado de residentes colostomizados y con sondas, así como en la administración de comida mediante jeringuilla.

- En ausencia del enfermero podrá hacer la prueba de glucosa, utilizar la vía subcutánea para administrar insulina y heparina a los usuarios, siempre que la dosis y el seguimiento del tratamiento se realice por personal médico o de enfermería.

- Acompañar al usuario o usuaria en la realización de actividades para facilitar el mantenimiento y mejora de las capacidades físicas y motoras, así como en la realización de actividades programadas, ya sean para citas médicas, excursiones, gestiones, etc., facilitando la participación activa de la persona usuaria en las mismas.

- Colaborar en la aplicación de técnicas de prevención de accidentes, de acuerdo a los protocolos establecidos y a las indicaciones del superior responsable.

- Colaborar con el TASOC en la animación y dinamización de la vida diaria de la Institución.

- Ayudar al usuario y usuaria en la realización de las actividades y ejercicios de mantenimiento y, siguiendo las orientaciones de los profesionales competentes.

- Sin que en ningún caso suponga la sustitución del personal contratado específicamente para la limpieza habitual, podrá realizar la limpieza e higiene de utensilios, ropa y estancias, cuando en el servicio existan circunstancias que así lo requieran.

- Apoyar y estimular la comunicación de las personas usuarias favoreciendo su desenvolvimiento diario y su relación social.

- Colaborar con el equipo interdisciplinar en la integración de los familiares de las personas usuarias en la vida del centro.

- Guardar absoluto silencio sobre la patología y el plan de cuidados individualizado del personal usuario, así como de cualquier asunto referente a su intimidad, y siempre actuará en coordinación y bajo la responsabilidad de profesionales de quienes dependan directamente.

- Efectuar la limpieza y mantenimiento de los enseres de los usuarios, colaborar en mantener ordenadas las habitaciones, recoger la ropa, llevarla a la lavandería, encargarse de la ropa personal de los usuarios y hacer las camas en función de las necesidades de cada usuario de acuerdo a los criterios de calidad establecidos, con la lencería limpia, ausencia de arrugas y humedad, en la posición adecuada, con especial atención a los pliegues corporales y otras zonas de especial riesgo, respetando la intimidad del usuario.

- Comunicar las incidencias que se produzcan sobre la salud de los/las usuarios/as. Observar y registrar en el libro de incidencias cualquier cambio de comportamiento y/o físico detectado.

Dispondrán de la titulación o habilitación requerida y/o experiencia precisa para el desarrollo de sus funciones en función de lo regulado en la normativa vigente",

23 "Desarrollará las funciones que se detallan a continuación así como aquellas que le sean solicitadas y que tengan relación con las mismas y/o con su titulación, habilitación o competencia profesional.

Se entiende por actividades de atención personal las siguientes:

- El aseo e higiene personal, habitual o especial, arreglo personal, ducha y/o baño, incluida la higiene bucal.

- Ayuda personal para el vestido, calzado y la alimentación.

- Transferencias, traslados y movilización dentro del hogar.

- Actividades de la vida diaria necesarias en la atención y cuidado del usuario.

- Estimulación y fomento de la máxima autonomía y participación de las personas atendidas en la realización de las actividades básicas de la vida diaria.

- Fomento de hábitos de higiene y orden.

- En personas con alto riesgo de aparición de úlceras por presión, prevenir éstas mediante una correcta higiene, cuidados de la piel y cambios posturales.

- Ayuda en la administración de medicamentos que tenga prescritos la persona usuaria.

- Cuidados básicos a personas incontinentes.

- Ayuda para la ingestión de alimentos.

- Fomento de la adecuada utilización de ayudas técnicas y adaptaciones pautadas.

- Recogida y gestión de recetas y documentos relacionados con la vida diaria de la persona usuaria.

- Avisar al coordinador/a correspondiente de cualquier circunstancia o alteración en el estado de la persona usuaria, o de cualquier circunstancia que varía, agrave o disminuya las necesidades personales o de vivienda de la persona usuaria.

Se entiende por atención a las necesidades del domicilio las siguientes: 
Grupo 5 dentro del personal auxiliar aparece el Personal Limpieza y Lavandería/Planchado ("es el personal que con responsabilidad restringida y dependiendo del/la Gobernante/a o la Dirección realiza funciones de limpieza, lavado y planchado"24). De leer con atención las tareas y funciones encomendadas a estos dos últimos grupos profesionales cabe observar que las actividades calificadas como esenciales y que permiten a la persona asistida seguir realizando las actividades imprescindibles de su vida son las realizadas por los grupos profesionales situados en la base de la pirámide de clasificación, llevando aparejada esa situación el salario base más bajo y la cuantificación de los complementos más escasa, como se muestra en las tablas salariales correspondientes ${ }^{25}$ ).

- Mantenimiento de limpieza o ayuda a la limpieza de la vivienda, salvo casos específicos de necesidad que sean determinados por el técnico responsable.

- Preparación de alimentos en el hogar o traslado de los mismos al domicilio.

- Lavado a máquina, planchado, repaso y organización de la ropa dentro del hogar.

- Apilación de las ropas sucias y traslado en su caso para su posterior recogida por el servicio de lavandería.

- Adquisición de alimentos y otras compras de artículos de primera necesidad por cuenta de la persona usuaria.

- Tareas de mantenimiento básico habitual de utensilios domésticos y de uso personal, que no requieran el servicio de un especialista (cambio de bombillas, cambio de bolsa de aspiradora, sustitución de pilas).

Apoyo familiar y relaciones con el entorno: Se incluyen dentro de este tipo de actividades las siguientes:

- Compañía para evitar situaciones de soledad y aislamiento.

- Acompañamiento fuera del hogar para posibilitar la participación de la persona usuaria en actividades de carácter educativo, terapéutico y social.

- Facilitar actividades de ocio en el domicilio.

- Apoyo y acompañamiento para la realización de trámites de asistencia sanitaria y administrativos.

- Desarrollo de la autoestima, la valoración de sí mismo y los hábitos de cuidado personal, evitando el aislamiento.

- Potenciar y facilitar hábitos de convivencia y relaciones familiares y sociales.

- Fomentar estilos de vida saludable y activos.

- Apoyo y seguimiento de las pautas prescritas ante situaciones de conflicto que se generen en el seno de la familia.

- Cuidado y atención de los menores, tanto en el entorno del hogar como en acompañamientos a centros escolares, de ocio, sanitarios y otros

Dispondrán de la titulación o habilitación requerida y/o experiencia precisa para el desarrollo de sus funciones en función de lo regulado en la normativa vigente".

${ }^{24}$ Desarrollará las funciones que se detallan a continuación así como aquellas que le sean solicitadas y que tengan relación con las mismas y/o con su habilitación o competencia profesional:

- Realizar las tareas propias de comedor-office, poniendo un cuidado especial en el uso de los materiales encomendados.

- Realizar las funciones propias de lavandería, lencería, uso y atención de la maquinaria, tener cuidado de la ropa de las personas usuarias y del centro, y dar la mejor utilización a los materiales.

- Realizar las tareas propias de limpieza de las habitaciones y zonas comunes (camas, cambios de ropa, baños, ventanales y balcones, mobiliario etc.) procurando ocasionar las menores molestias a las personas usuarias.

- Mantener siempre limpia y a punto la ropa de las personas usuarias, tanto la personal como la ropa de cama, toallas, etc., así como su recogida, clasificación y reparto posterior.

- Comunicar a su jefatura inmediata las incidencias o anomalías observadas en el desarrollo de sus tareas.

Dispondrán de la habilitación requerida y/o experiencia precisa para el desarrollo de sus funciones en función de lo regulado en la normativa vigente".

${ }^{25}$ Por ejemplo, Resolución de 19 de marzo de 2019, de la Dirección General de Trabajo, por la que se registran y publican la revisión y las tablas salariales para 2019 del VII Convenio colectivo marco estatal de servicios de atención a las personas dependientes y desarrollo de la promoción de la autonomía personal. 
La mayor diferencia entre el trabajo en residencias de la tercera edad y la prestación de ayuda a domicilio nace en el lugar de la prestación: bien en el domicilio privado de la persona atendida, o bien en el lugar propiedad de la empresa. En consecuencia, la infraestructura requerida en uno y otro caso hace que la inversión necesaria y las propias condiciones laborales sean distintas, así como también la articulación administrativa de la misma. De un lado, los servicios residenciales están regulados autonómicamente en cuanto hace a espacios y necesidades habitacionales, de salud y de ocio y, pese a la diversidad de normativa aplicable, varias Comunidades Autónomas se han ocupado en detallar las necesidades de personal requeridas para proporcionar una atención de calidad y recíprocamente (para personas usuarias y trabajadoras) apostar por un trabajo digno, mientras que en otras únicamente se hace referencia a personal "suficiente" en relación con los requerimientos de la atención debida. De otro, el servicio de ayuda a domicilio es intensivo en mano de obra pero no precisa de una inversión en costosos bienes y herramientas y usualmente es objeto de colaboración público-privada con la Administración Pública correspondiente.

\section{Limpiadoras y "kellys" entre la subcontratación y las empresas multiservicios.}

Dentro de las tareas de cuidados es preciso incorporar también aquella dedicada a la limpieza (sin entrar a valorar la relación laboral especial, objeto de atención en el apartado correspondiente), bien sea en una empresa o de forma especializada en hoteles.

En ambos casos, esa actividad ha venido siendo desempeñada por mujeres, escasamente pagada y reconocida socialmente, y en los últimos años ha sido objeto de subcontratación por la principal, dentro de un deliberado proceso de empequeñecimiento de las estructuras empresariales, precisamente por no precisar de la aportación de complejos medios materiales $^{26}$. Al tiempo, el proceso de adelgazamiento de las principales discurre paralelo a la creación de entramados satélite de las anteriores, bien especializadas en determinado tipo de actividades (como sucede con la limpieza) o bien, lo que todavía es más preocupante desde el punto de vista de los implicados, en consorcios empresas que abarcan un sinfín de sectores dispares. Dichas entidades desempeñan una función cercana a la intermediación, o a la cesión ilegal a través de estas "contratas inmateriales" o "desmaterializadas"27.

Son las comúnmente conocidas como empresas multiservicios, también denominadas como "empresas de servicios múltiples", de "gestión integral de servicios" u "outsourcing global", las cuales han sido definidas como "sociedades con objeto social amplio", que no están dedicadas a una actividad o servicio concreto, sino, al contrario, prestan una pluralidad de cometidos de muy diversa índole ${ }^{28}$. Esta aparición ha supuesto también un cambio cualitativo en la externalización pues se ha pasado de la "especialización"

\footnotetext{
26 ÁLVAREZ CUESTA, Henar, La precariedad en el sector del arte: un estatuto del artista como propuesta de solución. Albacete: Bomarzo, 2019.

27 VICENTE PALACIO, Aranzazu, Empresas multiservicios y precarización del empleo. El trabajador subcedido. Barcelona: Atelier, 2016, pp. 26-27.

28 ALAMEDA CASTILLO, M ${ }^{\mathrm{a}}$ Teresa, "La cesión de trabajadores a través de empresas multiservicios", Relaciones laborales, $\mathrm{n}^{\circ} .2$, 2005, pp. 353 y ss.
} 
característica de las empresas contratistas a su "polivalencia", de manera que son empresas cuyo objeto social está continuamente en expansión, en función de las demandas de los clientes, proceso que ha sido posible porque buena parte de los servicios requeridos y prestados por dichas empresas no necesitan de una gran inversión e incluso es factible que al desarrollar el trabajador la prestación laboral en la empresa cliente los medios que utiliza sean propiedad de esta" 29 , convirtiéndose, en la práctica, en vías baratas para rebajar las condiciones laborales ${ }^{30}$. En el caso analizado, entre otros varios, destaca la subcontratación de ocupaciones accesorias como la limpieza, donde coexisten un reducido número de empresas multiservicios de gran tamaño y ámbito estatal (muchas veces formando parte de grupos de empresas con la principal y alguna ETT $^{31}$ ) y un amplio $\mathrm{y}$ heterogéneo conjunto de pequeñas empresas, de ámbito territorial reducido $\mathrm{y}$ específico $^{32}$, que son intensivas en mano de obra pero precisan de muy escasa infraestructura material.

A la hora de analizar la precariedad (causas y factores) en este tipo de corporaciones, resulta necesario distinguir, en primer lugar, si la actividad desarrollada por los trabajadores de la multiservicios supone cesión ilegal; y en segundo, constatada la legalidad de la externalización, ahondar en el convenio colectivo aplicable a su actividad, con el fin último de propiciar la extensión de las superiores condiciones laborales de la principal.

Así, la precariedad derivaba de la vinculación de los contratos por obra y servicio a la duración de la contrata, considerándose hasta un reciente pronunciamiento del Tribunal Supremo $^{33}$, justa causa de finalización la terminación de aquella ${ }^{34}$; la incorporación en el clausulado convencional de causas de extinción de los contratos temporales de la finalización ante tempus de la relación mercantil; y la progresiva desaparición de los mecanismos subrogatorios previstos en los convenios colectivos, conduce a la creación de un subtipo de trabajador precario, los "subcedidos" 35 .

La ausencia de regulación legal específica ha creado un "limbo legal" que ha permitido una competitividad fundada en el abaratamiento de los precios de los servicios contratados vía reducción de costes laborales ${ }^{36}$, conseguido mediante la elusión del

\footnotetext{
${ }^{29}$ VICENTE PALACIO, Aránzazu, "Empresas multiservicios y precarización en el empleo", Gaceta Sindical, $n^{\circ} .29,2017$, p. 277.

${ }^{30}$ NIETO ROJAS, Patricia, "La protección de los trabajadores de las empresas multiservicios. Propuestas legales, convencionales y judiciales", Revista Internacional y Comparada de Relaciones Laborales y Derecho del Empleo, Vol. 6, nº. 2, 2018, p. 11.

${ }^{31}$ MERINO SEGOVIA, Amparo, "La problemática legitimación de las representaciones sociales para negociar y suscribir convenios colectivos en las empresas multiservicios", en La negociación colectiva como instrumento de gestión del cambio. Madrid: Cinca, 2017, p. 135.

${ }^{32}$ ALFONSO MELLADO, Carlos Luis, et alii: "Conclusiones generales", en La negociación colectiva en las empresas multiservicios: un balance crítico. Madrid: Francis Lefebvre/1º de mayo, 2018, p. 511.

${ }^{33}$ STS 29 diciembre 2020 (Rec. 240/2018).

${ }^{34}$ Entre otros muchas, STSJ Castilla y León/Valladolid 23 octubre 2014 (Rec. 1230/2014).

${ }^{35}$ VICENTE PALACIO, Aránzazu, Empresas multiservicios y precarización del empleo. El trabajador subcedido, cit., pp. 107 y ss.

${ }^{36}$ ALFONSO MELLADO, Carlos Luis, et alii: "Conclusiones generales”, cit., p. 511.
} 
convenio sectorial correspondiente ${ }^{37}$. Los propios Tribunales han considerado "preocupante la proliferación en el mercado de empresas de externalización de servicios que, basadas en una reducción de los costes laborales por el sencillo mecanismo de constituir mercantiles a las que se dota de un convenio colectivo propio inferior siempre a los precios de los convenios de sector, que compiten en condiciones ventajosas con otras empresas con costes más elevados (es palmario para las ETT que han de abonar el mismo salario que la usuaria) y se aprovechan en situación de crisis económica de la depreciación del valor de los recursos humanos" ${ }^{\prime 3}$.

Este ahorro para la empresa cliente deriva mayormente del empeoramiento de las condiciones de trabajo para los trabajadores subcontratados, en el caso analizado, limpiadoras: los salarios son inferiores, las jornadas son mayores y existe un incremento en la distribución irregular de las mismas ${ }^{39}$. Y esta rebaja se realiza a través de los convenios de empresa, debido a que se negocia "normalmente con representaciones no sindicalizadas, que facilitan la implantación de las estrategias empresariales, centradas en minorar drásticamente los salarios y las condiciones laborales, alejándose de las condiciones fijadas en los convenios sectoriales de referencia, cuando no autoexcluyéndose totalmente de ellos"40. Al final, "el empleo que se crea en estas empresas es un empleo precario, en todas las fases de la relación laboral (constitución, vigencia del contrato y extinción del mismo) por la concurrencia de la deslegalización y la cuestionable negociación colectiva que se viene desarrollando en las mismas" ${ }^{41}$.

Como muestra ejemplificativa de las consecuencias laborales que supone la externalización patológica, baste mencionar a una de las profesiones, muy feminizada, que ha sufrido este proceso de descentralización paulatina de su actividad: las camareras de hotel, asociadas bajo la denominación de "kellys", "cuyas condiciones están muy por debajo de lo pactado en los convenios provinciales de hostelería" ${ }^{42}$. Ven rebajada por esta vía su remuneración y ampliados hasta el infinito los objetivos a cumplir (número de habitaciones preparadas).

\section{Las siempre invisibles empleadas de hogar}

Como último grupo al cual incorporar en este rápido recorrido de profesiones de cuidados precarias destaca la tradicional (la cual, en sus orígenes aúna a todas) prestación de servicios para el hogar familiar. "Según la EPA en el último trimestre de 2019 había 580.500 personas como empleadas del hogar, mientras que en el tercer trimestre de 2020

\footnotetext{
37 ESTEVE SEGARRA, Amparo, "Criterios para la determinación de actividades desarrolladas por empresas multiservicios que contarían con un convenio sectorial de referencia”, en Congreso Nacional de la AEDTSS. Madrid: Iustel, 2018.

${ }^{38}$ SAN 30 mayo 2014 (Sent. 99/2014).

39 VICENTE PALACIO, Aránzazu, Empresas multiservicios y precarización del empleo. El trabajador subcedido, cit., pp. 116 y ss.

40 GONZÁLEZ CALVO, Mercedes, "Presentación", en La negociación colectiva en las empresas multiservicios. Un balance crítico. Madrid: Fundación $1^{\circ}$ Mayo/Lefebvre el Derecho, 2018, p. 9.

${ }^{41}$ VICENTE PALACIO, Aránzazu "Empresas multiservicios y precarización en el empleo”, cit., p. 275.

${ }^{42}$ https://www.ccoo-servicios.es/hosteleria/camareraspiso/html/42351.html.
} 
esta cifra se ha reducido hasta las 529.100 personas, unas 50.000 menos"43 (cabe entender que dicha disminución deriva de la crisis económica derivada de la pandemia y de las propias medidas de seguridad.

Su prestación de servicios calificada como relación laboral especial, viene regulada por un reglamento específico (RD 1620/2011, de 14 de noviembre), el cual, y pese a su actualización en el año $2011^{44}$, a día de hoy se sigue mostrando insuficiente para afrontar la nuevas circunstancias y luchar contra la desigualdad sempiterna de tal colectivo, en particular con un conjunto de trabajadoras extranjeras sin las correspondientes autorizaciones de trabajo que se refugian en este ámbito laboral, pudiendo ser así pasto de injusticias y excesos por parte de los empleadores; además, se vuelve a insistir que quienes más sufren las precarias condiciones laborales en él reguladas van a ser las mujeres, principales perjudicadas (y entre ellas, las inmigrantes), en tanto son el colectivo más numeroso dentro de los empleados de hogar, hasta el punto de feminizar su denominación ${ }^{45}$.

\section{La precariedad unida a las condiciones de trabajo en el sector cuidados}

Las pésimas condiciones de trabajo padecidas por quienes trabajan en el sector cuidados refuerzan las desigualdades de género, clase y etnia ${ }^{46}$. Desde luego, y como se ha visto supra, no cabe simplificar colectivos diversos dado que no conforman un "grupo homogéneo: existen diferencias y jerarquías entre las trabajadoras del cuidado, también en términos de remuneración, condiciones de trabajo y estatus" ${ }^{27}$. Con todo, hay dos cualidades que las distinguen en distintos grados presentes: la invisibilidad y la precariedad $^{48}$.

\footnotetext{
${ }^{43}$ POQUET CATALÁ, Raquel, "Covid-19, crisis sanitaria, económica y laboral: ¿hacia un trabajo decente en el trabajo doméstico?", Revista Internacional y Comparada de relaciones laborales y derecho del empleo, vol. 9, $\mathrm{n}^{\circ} .1,2021$, p. 248.

44 "Pese a que el RD 1620/2011 supuso una indudable mejora en el régimen jurídico de los trabajadores domésticos, en relación con el que había previsto el RD 1424/1985, aún quedan diferencias de trato no justificadas en perjuicio de estos trabajadores", GARCÍA TESTAL, Elena, "La extinción del contrato de trabajo de los trabajadores domésticos en España: un régimen jurídico injustificadamente diferenciado", Revista Lex Social: Revista de Derechos Sociales, nº. 2, 2019, p. 295.

45 ÁLVAREZ CUESTA, Henar, La precariedad laboral. cit., pp. 85 y ss.

${ }^{46}$ CARRASCO, Cristina; BORDERÍAS, Cristina y TORNS, Teresa, "El trabajo de cuidado: antecedentes históricos y debates actuales", Revista de Economía Crítica, nº. 13, 2012, p. 46.

${ }^{47}$ OIT, El trabajo de cuidados y los trabajadores del cuidado para un futuro con trabajo decente, 2018, p. 13.

${ }^{48}$ MOLERO MARAÑÓN, M.L., "Las trabajadoras del cuidado: por un futuro del trabajo decente", cit., p. 46.
} 
Hasta el momento no existe una definición común de "empleo precario", "mal empleo" o "trabajo indecente" 49 , pero sí una serie de factores o características que concurren en él, esbozadas a modo de meras pinceladas ${ }^{50}$ por el propio Parlamento Europeo ${ }^{51}$ :

-- escasa o nula seguridad laboral debido al carácter temporal del trabajo o a la escueta dedicación, como es el caso de contratos de trabajo a tiempo parcial no voluntarios y a menudo marginales, $\mathrm{y}$, en algunos Estados miembros, horarios imprecisos y funciones que varían debido al trabajo "a la carta";

-- protección rudimentaria frente al despido y tutela social insuficiente inherente;

-- remuneración inadecuada para llevar una vida digna;

-- derechos y prestaciones de protección social nulos o limitados;

-- protección débil contra cualquier forma de discriminación;

-- perspectivas reducidas de progreso en el mercado laboral o en materia de desarrollo y formación;

-- bajo nivel de derechos colectivos;

-- entorno laboral que no respeta las normas mínimas de salud y seguridad ${ }^{52}$.

Al final, este término hace referencia a "trabajadores marginados del bienestar institucionalmente garantizado por el sistema legal y de negociación colectiva y sus respectivas redes de cobertura protectora y desmercantilizadora"53; de manera que el ejército de precarios está integrado "por trabajadores eventuales, parados, a tiempo parcial, a la llamada o a demanda, jóvenes, mujeres, trabajo negro, atípico o sumergido, etc." ${ }^{54}$.

Dentro del mismo, las mujeres dedicadas al sector analizado, y como se ha visto supra, ocupan "trabajos fuertemente marcados por una segregación sexual horizontal, determinada por los estereotipos de género que han atribuido, desde siempre, a las mujeres el rol social de los cuidados". Si a ello se une la perspectiva androcéntrica que

\footnotetext{
${ }^{49}$ DE LA VILLA GIL, Luis Enrique, "Do ut facias: entorno a los estímulos de la contratación laboral", Revista de la Facultad de Derecho de la Universidad Complutense de Madrid, $\mathrm{n}^{\mathrm{a}}$. 23, 1999, pp. 567-583.

${ }^{50}$ Siguiendo a ÁLVAREZ CUESTA, Henar, La precariedad laboral. cit., pp. 15 y ss.

${ }^{51}$ Resolución del Parlamento Europeo, de 4 de julio de 2017, sobre las condiciones laborales y el empleo precario (2016/2221(INI)).

${ }^{52}$ RODRÍGUEZ ESCANCIANO, Susana y ÁLVAREZ CUESTA, Henar, Trabajo autónomo y trabajo por cuenta ajena: nuevas formas de precariedad laboral. Albacete: Bomarzo, 2019.

${ }^{53}$ MONEREO PÉREZ, José Luis, "El Derecho del Trabajo en el umbral del siglo XXI: la nueva fase del Derecho del Trabajo", Lan Harremanak, no. 2, 2000, p. 252 y RODRÍGUEZ ESCANCIANO, Susana, "La crisis en la identidad del modelo 'clásico' de contrato de trabajo: la incidencia del paro y la precariedad", La Ley, $\mathrm{n}^{\circ} .4,2002$, p. 1859.

${ }^{54}$ MONEREO PÉREZ, José Luis, "Evolución y futuro del Derecho del Trabajo: el proceso de racionalización jurídica de la 'cuestión social”', Relaciones Laborales, nº. 15-16, 2001, p. 32.
} 
todavía persiste en el Derecho español se termina infravalorando las profesiones con amplia presencia femenina ${ }^{55}$.

Este círculo vicioso acaba por generar empleos de mala calidad para las trabajadoras del cuidado que conducen al trabajo de cuidados de mala calidad. Y ello redunda en "detrimento del bienestar de quienes reciben los cuidados, de quienes los prestan, y también de las cuidadoras no remunerados que disponen de menos opciones"56.

Como fácilmente puede apreciarse, la desprotección surge porque la propia normativa laboral presenta puntos oscuros, bien sea por su utilización espuria, bien por dejar "agujeros" en su regulación capaces de desvirtuar la finalidad tuitiva del ordenamiento ${ }^{57}$; pero también cabe encontrar, sin indagar demasiado, que las normas laborales excluyen expresamente a algunos colectivos de su ámbito de aplicación ${ }^{58}$ (como sucede con las cuidadoras no profesionales).

En cuanto a las concretas características que permiten calificar un trabajo como precario y por cuanto aquí interesa, destaca el trabajo sumergido e invisible, la temporalidad, la parcialidad y de forma transversal, los bajos salarios asociados a la escasa valoración de estas actividades.

En cuanto hace al trabajo oculto, "existe un consenso generalizado sobre los efectos negativos de la economía sumergida y, en particular, del trabajo no declarado, como elementos que distorsionan el mercado y dificultan el sistema de protección social y garantías de los trabajadores. En primer lugar, los perjuicios del trabajo no declarado se proyectan sobre la disminución, cuando no eliminación, de las posibilidades de protección social de las propias trabajadoras afectadas y de sus condiciones de vida y de trabajo en un momento en el que precisamente pueden ser más vulnerables ante las contingencias diversas relacionadas con el ciclo económico. Es probablemente el caso de mayor precariedad, el que más parecidos tiene con la ley de la selva y una negación de su propia condición" $" 59$. Y este rasgo afecta a las cuidadoras no profesionales, que se ven expulsadas ex lege del manto tuitivo del Estatuto de los Trabajadores, y a las empleadas de hogar, por la facilidad que supone su trabajo intra muros del hogar familiar y su vulnerabilidad, muchas veces derivada de su situación administrativa irregular.

Respecto a la temporalidad, y pese a que el principio de estabilidad en el contrato de trabajo es el paradigma sobre el cual se construye el sistema de relaciones laborales, el mal llamado mercado de trabajo ha generado empleo precario desde hace más de veinte

${ }^{55}$ LÓPEZ ANIORTE, Ma del Carmen y FERRANDO GARCÍA, Francisca, "Precariedad y desprotección social del trabajo de limpieza y cuidados ante la situación de crisis sanitaria provocada por la Covid-19", Revista Internacional y Comparada de relaciones laborales y derecho del empleo, vol. 9, $\mathrm{n}^{\circ} .1,2021$, p. 218.

${ }^{56}$ OIT, El trabajo de cuidados y los trabajadores del cuidado para un futuro con trabajo decente. cit., p. 15.

57 OJEDA AVILÉS, Antonio y GORELLI HERNÁNDEZ, Juan, Los contratos de trabajo temporales. Madrid: Iustel, 2006, p. 17.

${ }^{58}$ SERVAIS, Jean Michel, International labour market Law. La Haya: Kluwer, 2005, p. 89.

${ }^{59}$ CAMINO FRÍAS, Juan José, Lucha contra el empleo irregular y el fraude a la Seguridad Social. Valladolid: Lex Nova, 2013, p. 7. 
años a través de la contratación temporal, la cual ha acabado por convertirse no solo en la vía de entrada al mundo laboral, sino la inercia en la cual se asienta en demasiados sectores productivos, y en particular para los más jóvenes. La precarización laboral es, en este sentido, doble: el resultado de la irregular utilización del contrato temporal y la utilización lícita de una posibilidad brindada por la norma ${ }^{60}$ o ampliada hasta el límite (y más allá) por los Tribunales del orden social ${ }^{61}$. Su aplicación al sector analizado es transversal, en tanto afecta a quienes prestan servicios en residencias y en ayuda a domicilio, a las limpiadoras y a las fácilmente despedidas empleadas de hogar.

En muchas de las actividades del sector cuidados (especialmente en la ayuda a domicilio) el contrato a tiempo parcial es el más utilizado (en la Unión Europea un 32\% de mujeres están contratadas a tiempo parcial frente a un $10 \%$ de hombres ${ }^{62}$ ) y de nuevo su generalización avoca a potenciales efectos nocivos y a competir a la baja en la regulación de condiciones de trabajo ${ }^{63}$. Este vínculo laboral a acabado por potenciar "la discriminación por razón de género, nos aleja de los estándares de un trabajo decente y aumenta la posibilidad de sufrir violencia en el trabajo"64.

La flexibilización del tiempo de trabajo que lleva aparejada e incrementada merced a los últimos cambios sufridos podría llegar a suponer su dedicación o su disponibilidad, casi a tiempo completo, con una contraprestación reducida. Esto significaría, además, una cierta transmisión del riesgo empresarial, derivado de las fluctuaciones de la demanda, a la trabajadora ${ }^{65}$ en virtud del uso de los diversos tipos de horas complementarias.

Como rasgo común a la mayoría de actividades del sector de los cuidados, las trabajadoras sufren riesgos físicos, vinculados con los movimientos repetitivos y los continuos levantamientos de peso, y psicosociales (carga mental, estrés, burn out, desgaste emocional) derivados de la interacción continua con personas mayores y/o dependientes.

En fin, por cuanto hace a la retribución y dado el escaso valor otorgado a la actividad desempeñada, ocupan, como se ha visto, los grupos profesionales inferiores que tienen aparejada una retribución casi equiparada al Salario Mínimo Interprofesional, y muchas veces no se aplica el convenio sectorial, sino el empresarial, el cual establece una paga mensual inferior al referente superior. Sin olvidar tampoco que las trabajadoras que

\footnotetext{
${ }^{60}$ LAHERA FORTEZA, Jesús, Los contratos temporales en la unificación de doctrina. Madrid: La Ley, 2001, p. 72.

${ }^{61}$ Los Tribunales desoyen su obligación de apoyar las interpretaciones más favorables a la salvaguarda de la estabilidad en el empleo, DE LA VILLA GIL, Luis Enrique, "Contratación temporal", en Unificación de doctrina del Tribunal Supremo en materia laboral y procesal laboral. Estudios en homenaje al Profesor Doctor Efrén Borrajo Dacruz. Valencia: Tirant lo Blanch, 1999, p. 160.

${ }^{62}$ EUROPEAN INSTITUTE FOR GENDER EQUALITY, EIGE, Gender inequalities in care and consequences for the labour market, Luxemburgo: Publications Office of the European Union, 2021, p. 20. ${ }^{63}$ GONZÁLEZ DEL REY, Ignacio, El contrato de trabajo a tiempo parcial. Pamplona: Aranzadi, 1998, p. 204 y MARTÍN VALVERDE, Antonio, "El discreto retorno del contrato de arrendamiento de servicios", en Cuestiones actuales de Derecho del Trabajo. Estudios ofrecidos por los catedráticos españoles de Derecho del Trabajo al Prof. Manuel Alonso Olea. Madrid: MTSS, 1990, p. 233.

${ }^{64}$ ALTÉS TÁRREGA, Juan Antonio, "El contrato a tiempo parcial: reflexiones sobre su régimen jurídico, flexibilidad y precariedad", Revista Lex Social: Revista de Derechos Sociales, n'. 2, 2019, p. 575.

${ }^{65}$ GONZÁLEZ DEL REY, Ignacio, El contrato de trabajo a tiempo parcial, cit., p. 241.
} 
desarrollen una jornada de trabajo muy reducida tendrán problemas para lograr una retribución suficiente, tal y como es exigida en el artículo $35 \mathrm{CE}^{66}$. Con ello, la retribución resultante sufrirá un doble efecto adverso: la subvaloración de los puestos de trabajo que habitualmente se desempeñan y correlativamente de su retribución y la disminución proporcional que corresponda ${ }^{67}$.

\section{El trabajo decente como antídoto de la precariedad.}

El trabajo decente, respuesta de la OIT a la globalización y a la crisis, es un concepto ético-jurídico y un marco integrador de los pilares del mandato constitucional de la OIT que defiende y se define como la promoción del empleo, la protección de los derechos en el trabajo, la extensión de la protección social y el fomento del diálogo social, así como el respeto de la igualdad de oportunidades y trato para todas las mujeres y hombres ${ }^{68}$.

Este término expresa, de forma concisa, el objetivo de la OIT de luchar por la justicia social en un mundo globalizado. La OIT aspira a dar un rostro humano a la globalización ${ }^{69}$. En resumen, se trata de un "trabajo productivo para los hombres y mujeres en condiciones de libertad, equidad, seguridad y dignidad humana"70.

Por ello, desde estas líneas se plantea como objetivo a lograr un trabajo de cuidados decente, apoyado en políticas transformadoras ${ }^{71}$ (asumidas a nivel legal, convencional y cultural), en tanto "el empleo de buena calidad relacionado con el cuidado que promueve la igualdad de género y beneficia a todas las partes interesadas (los beneficiarios de los cuidados, los trabajadores y trabajadoras del cuidado, y las cuidadoras y cuidadores no remunerados) es posible y factible"72. En consecuencia, las propuestas de solución apuntadas precisan un cambio en tres aspectos fundamentales: legal, convencional y cultural.

\footnotetext{
${ }^{66}$ MERINO SENOVILLA, Henar, "El trabajo a tiempo parcial: La nueva delimitación y las líneas fundamentales de su contenido", Revista de Derecho Social, nº. 5, 1999, p. 276.

${ }^{67}$ SALDAÑA VALDERAS, Eva, La discriminación retributiva por razón de género. Sevilla: Mergablum, 2004.

${ }^{68}$ GIL Y GIL, José Luis, “Concepto de trabajo decente”, Relaciones Laborales, $\mathrm{n}^{\circ} .15-16,2012$, pp. 77 120.

${ }^{69}$ GIL Y GIL, José Luis, “Trabajo decente y reformas laborales”, Revista Derecho Social y Empresa, no. 7, 2017, p. 3.

${ }^{70}$ ROJO TORRECILLA, Eduardo, "El trabajo decente en normas y documentos de la OIT", en Congreso Interuniversitario OIT sobre el futuro del trabajo. Madrid: Ministerio de Trabajo y Economía Social/OIT, 2020, p. 97.

${ }^{71}$ Siguiendo a RODRÍGUEZ RODRÍGUEZ, Emma, "De la conciliación a la corresponsabilidad en el tiempo de trabajo: un cambio de paradigma imprescindible para conseguir el trabajo decente", Revista Lex Social: Revista de Derechos Sociales, $\mathrm{n}^{\circ} .11,2021, \mathrm{p} .71$.

${ }^{72}$ OIT, El trabajo de cuidados y los trabajadores del cuidado para un futuro con trabajo decente. cit., p. 17.
} 


\section{La ley como motor de cambio.}

La precariedad padecida desde hace tanto tiempo y en múltiples aspectos hace imprescindible proponer auténticas transformaciones legales, no bastando en este caso (aunque sí siendo indudablemente necesarios), los oportunos cambios convencionales.

Por ello, conviene modificar, como desde hace tiempo se viene demandando, en primer lugar, la integración de las cuidadoras no profesionales en el ámbito productivo con un estatuto propio, bien a través de su consideración como una modalidad de los trabajadores autónomos económicamente dependientes (debido a su posible vinculación familiar con la persona dependiente) o bien, de no existir ese impedimento, dentro de una relación laboral especial. En ambos casos, es preciso regular el derecho al oportuno descanso y las medidas de protección social oportunas, con el fin de ir avanzando hacia la profesionalización de dichos servicios.

En segundo lugar, es preciso aquilatar la regulación de las empresas multiservicios y del marco que fija el ámbito de actuación de la subcontratación ${ }^{73}$, con el fin de evitar las líneas de fuga que este tipo de unidades de producción utilizan para rebajar las condiciones laborales de sus trabajadores, en el caso estudiado, trabajadoras de la limpieza y camareras de hoteles. Así, se han propuesto dos posibles reformas del art. 42 ET para garantizar la igualdad en las condiciones laborales de los trabajadores subcontratados, de un lado imponer la aplicación del convenio sectorial aplicable a la subcontratista o bien, mucho más garantista, propiciar la igualdad de las condiciones (especialmente las salariales) que realmente se apliquen en la empresa principal y, por tanto, el convenio colectivo que se aplica a la propia empresa principal ${ }^{74}$.

La indebida utilización de los contratos temporales ha de ser objetivo constante de la Inspección de trabajo ${ }^{75} \mathrm{y}$, como mecanismo para desincentivar su uso fraudulento cabe proponer la elevación de las indemnizaciones por su término. En relación con el contrato a tiempo parcial, "debería apostarse por legislar reequilibrando el juego de intereses, revisando aquellos elementos que precarizan el trabajo parcial, impiden la elección voluntaria y que, además, crean impacto de género", a la vista de que "la actual regulación

\footnotetext{
${ }^{73}$ Por ejemplo, en LÓPEZ BALAGUER, Mercedes, "Trabajo precario y empresas multiservicios: una propuesta de solución legal", Revista Jurídica de los Derechos Sociales Lex Social, nª 1, Vol. 9, 2019.

${ }^{74}$ Apostando por la primera de las soluciones, pero entendiendo que "cabría completar la anterior propuesta añadiendo que sería posible seguir aplicando el convenio colectivo de empresa de la contratista o subcontratista, si dicho convenio de empresa hubiera tenido "garantías" tales como que lo hubieran negociado secciones o sindicatos más representativos o representativos o, al menos, los sindicatos o secciones sindicales legitimados para negociar convenios de empresa conforme al artículo 87.1 ET. Se podría modificar el ET en este sentido", GARCÍA-PERROTE ESCARTÍN, Ignacio, "La reforma del artículo 42 del Estatuto de los Trabajadores", Iuslabor, $\mathrm{n}^{\circ} .1,2019$, p. 3.

${ }^{75} \mathrm{Al}$ respecto, un análisis completo de su actuación en este concreto sector en FERNÁNDEZ GONZÁLEZ, Cristina, "El papel de la inspección de trabajo y seguridad social en el control del cumplimiento de la normativa aplicable", Revista Lex Social: Revista de Derechos Sociales, n. 2, 2019, pp. 520 y ss.
} 
convierte prácticamente el trabajo a tiempo parcial en un punto de llegada y no en el primer paso hacia un contrato a tiempo completo"76.

Por cuanto afecta a las empleadas de hogar, y desde luego apostando por una protección social completa (incluida la prestación por desempleo) ${ }^{77}$, parece necesario repensar las condiciones laborales reguladas en el reglamento específico y la exclusión ex lege de la prevención de riesgos laborales, habida cuenta tanto la indemnización más reducida en caso de improcedencia del despido, como las posibilidades de desistimiento del empleador, se pueden relacionar más con la aspiración de no gravar a este último excesivamente que con la relación de confianza que justifica la especialidad de la relación, por lo que, "el régimen de extinción del trabajo doméstico, en la medida en que supone una desprotección del empleado, presenta una disfunción de la existencia del trabajo doméstico como relación especial e incrementa el desequilibrio entre las partes y la precariedad de este tipo de prestaciones de servicios [y] no puede pues sino propugnarse la necesidad de equiparación de los empleados domésticos con los trabajadores comunes, pues la diferencia de régimen jurídico no deriva de las causas que justifican su especialidad"78.

\section{Buenas prácticas convencionales}

La llamada al cambio legal es complementaria (y no sustitutoria) a la incorporación de buenas prácticas en la negociación colectiva, habida cuenta "es de suma trascendencia que nuestros convenios colectivos sean evaluados en clave de perspectiva de género, para no incurrir en estas desigualdades carentes de una justificación objetiva y razonable, que vuelven a generar una discriminación indirecta por razón de sexo, por ser el colectivo femenino abrumadoramente mayoritario en dicha profesión"79.

En primer término, los convenios colectivos están comenzando a incorporar previsiones en tal sentido. Así, cabe destacar la apuesta por el $80 \%$ de los contratos indefinidos, la fijación de una duración mínima de la jornada parcial ${ }^{80}$ o la creación de un Observatorio

\footnotetext{
${ }^{76}$ ALTÉS TÁRREGA, Juan Antonio, "El contrato a tiempo parcial: reflexiones sobre su régimen jurídico, flexibilidad y precariedad”, cit., pp. 575-576.

${ }^{77}$ SANZ SÁEZ, Concepción, La protección social de las empleadas de hogar, Albacete: Bomarzo, 2017.

78 GARCÍA TESTAL, Elena, "La extinción del contrato de trabajo de los trabajadores domésticos en España: un régimen jurídico injustificadamente diferenciado", cit., p. 295.

79 MOLERO MARÃ̃ÓN, Ma Luisa, "Las trabajadoras del cuidado: por un futuro del trabajo decente", cit., p. 64.

80 "Estabilidad en el empleo: A fin de fomentar la contratación indefinida y de dotar de una mayor estabilidad a los contratos vigentes, se acuerda que todas las empresas afectadas por el presente convenio tendrán un $80 \%$ de personal, sobre la plantilla mínima que legalmente le sea exigida en cada situación, con contratos indefinidos y durante toda la vigencia de este convenio.

En el caso de empresas de nueva creación tendrán que alcanzarse los siguientes porcentajes:

- A la finalización del primer año de actividad, el $60 \%$.

- A la finalización del segundo año de actividad, el $80 \%$.

En consecuencia, los porcentajes máximos de contratación temporal, en cualquiera de las modalidades previstas en el presente convenio, serán del 20\%, con excepción del primer año de actividad en el caso de las empresas de nueva creación que será del 40\%. Quedan exceptuados de este cómputo los contratos de interinidad, en prácticas y para la formación y el aprendizaje", art. 18 VII Convenio marco estatal de servicios de atención a las personas dependientes y desarrollo de la promoción de la autonomía personal
} 
del empleo y del sector ${ }^{81}$ en el convenio sectorial de aplicación a las residencias de la tercera edad y a la ayuda a domicilio.

El siguiente paso consiste en mejorar las condiciones salariales de los grupos profesionales más bajos (más feminizados, más precarizados, se insiste) para superar la brecha salarial por razón de género ${ }^{82}$ y trasladar dicha mejora a los acuerdos subsectoriales o de empresa, capaces estos últimos de descolgarse en este punto.

También la negociación colectiva tiene (o ha de) asumir un relevante papel en la reacción a las empresas multiservicios. Desde hace algún tiempo, "algunos convenios, significadamente en sectores muy afectados por la descentralización productiva, incluyen mecanismos de subrogación convencional con el objetivo de garantizar el empleo de los trabajadores". Otra medida pasa por la inclusión en el ámbito funcional del convenio sectorial a este tipo de empresas o de actividades típicas, como es la limpieza ${ }^{83}$. La tercera se ha centrado en la regulación convencional de las circunstancias en las que se permite la subcontratación ${ }^{84}$.

\section{Valoración de los trabajos de cuidados como esenciales e imprescindibles}

La pandemia de COVID-19 ha puesto de manifiesto la fragilidad de las infraestructuras asistenciales, carentes de atención y suficiente financiación por parte de los poderes públicos, revelando, a la par, las duras consecuencias de este olvido. "Los trabajadores de los cuidados y de la atención sanitaria trabajadores sanitarios se han visto afectados de forma desproporcionada por el virus, y las medidas de cierre impuestas en toda la UE

(Resolución de 11 de septiembre de 2018, de la Dirección General de Trabajo, por la que se registra y publica el VII Convenio colectivo marco estatal de servicios de atención a las personas dependientes y desarrollo de la promoción de la autonomía personal (residencias privadas de personas mayores y del servicio de ayuda a domicilio), BOE núm. 229, de 21 de septiembre de 2018).

${ }^{81}$ Art. 19 Resolución de 11 de septiembre de 2018, de la Dirección General de Trabajo, por la que se registra y publica el VII Convenio colectivo marco estatal de servicios de atención a las personas dependientes y desarrollo de la promoción de la autonomía personal (residencias privadas de personas mayores y del servicio de ayuda a domicilio), BOE núm. 229, de 21 de septiembre de 2018.

${ }^{82}$ MARTÍNEZ MORENO, Carolina, Brecha salarial de género y discriminación distributiva: causas y vías para combatirlas. Madrid: Bomarzo, 2019.

${ }^{83}$ Aunque no sea suficiente, porque es necesario que se incluyan las empresas multiservicio, el V Acuerdo Laboral de ámbito estatal para el sector de hostelería (Resolución de 6 de mayo de 2015, de la Dirección General de Empleo, por la que se registra y publica el V Acuerdo Laboral de ámbito estatal para el sector de hostelería, BOE núm. 121, de 21 de mayo de 2015 incluye en el área funcional $4^{\mathrm{a}}$ a los camareros de piso, para "realizar de manera cualificada la limpieza y arreglo de las habitaciones y pasillos, así como del orden de los objetos de los clientes. Limpiar y ordenar las habitaciones, baños y pasillos entre las habitaciones de clientes. Controlar el material, productos de los clientes y comunicar a sus responsables las anomalías en las instalaciones y los objetos perdidos. Realizar la atención directa al cliente en las funciones propias de su área. Realizar las labores propias de lencería y lavandería”. Y a “d) Auxiliar Pisos y Limpieza: encargarse de manera no cualificada de las tareas auxiliares de limpieza y arreglo de pisos y áreas públicas. Preparar, transportar y recoger los materiales y productos necesarios para la limpieza y mantenimiento de habitaciones y áreas públicas e internas. Preparar las salas para reuniones, convenciones, etcétera. Limpiar las áreas y realizar labores auxiliares".

${ }^{84}$ MONEREO PÉREZ, José Luis, "La garantía de los derechos de los trabajadores en la subcontratación empresarial”, Derecho de las Relaciones Laborales, vol. 2, 2016, p. 129 y NIETO ROJAS, Patricia, "La respuesta de la negociación colectiva sectorial a las empresas multiservicios", Información Laboral, no. 7 , 2017. 
agravaron la tensión sobre los hogares que dependen de los servicios asistenciales externos". Dado que la pandemia mundial parece haber catalizado una revalorización del trabajo de cuidados a nivel social (tanto remunerado como no remunerado) en la economía, parece oportuno aprovechar este impulso para hacer que las estrategias de recuperación de la pandemia priorizaran este sector ${ }^{85}$, fomentando tanto las inversiones en la formación de las personas trabajadoras ("uno de los factores que influye y dificulta la profesionalización..., es la falta de reconocimiento de las cualificaciones que requieren muchas de estas actividades, cualificaciones que además favorecerían el reconocimiento social de esta actividad" y de quienes prestan servicios en la misma ${ }^{86}$ ), como en las posibilidades de desarrollo de las economías de cuidado y atención a las personas ${ }^{87}$. Si los cuidados son una responsabilidad colectiva de la sociedad, hay que actuar y legislar en consecuencia ${ }^{88}$.

Como última conclusión, y para la superación de la precariedad e invisibilización puesta de manifiesto en el trabajo de cuidados remunerado, resulta imprescindible una transformación en la valoración social de este tipo de actividades. Avanzar en la igualdad supone poner en el centro a las personas, tanto a quienes prestan servicios como a aquellos seres humanos que reciben esta prestación en sus múltiples manifestaciones. Si en tantas ocasiones se demanda un cambio de modelo, en este caso con un mayor motivo se tiene que poner el foco y valorar a quienes cuidan y protegen de forma amplia a las personas dependientes, de mayor edad y transversalmente a toda la sociedad y, en consecuencia, dignificar laboralmente esas prestaciones de servicios, en tantas ocasiones menospreciadas e invisibles.

\section{Bibliografía}

ALAMEDA CASTILLO, Ma Teresa, "La cesión de trabajadores a través de empresas multiservicios", Relaciones laborales, no. 2, 2005.

ALFONSO MELLADO, Carlos Luis, et alii: "Conclusiones generales", en La negociación colectiva en las empresas multiservicios: un balance crítico. Madrid: Francis Lefebvre $/ 1^{\circ}$ de mayo, 2018.

ALTÉS TÁRREGA, Juan Antonio, "El contrato a tiempo parcial: reflexiones sobre su régimen jurídico, flexibilidad y precariedad", Revista Lex Social: Revista de Derechos Sociales, $\mathrm{n}^{\circ} .2,2019$.

ÁLVAREZ CUESTA, Henar, La precariedad laboral. Albacete: Bomarzo, 2008.

\footnotetext{
${ }^{85}$ EUROPEAN INSTITUTE FOR GENDER EQUALITY, EIGE, Gender inequalities in care and consequences for the labour market, cit., p. 66.

${ }^{86}$ SANZ SÁEZ, Concepción, "Profesionalización efectiva del servicio doméstico. un trabajo pendiente", Revista Lex Social: Revista de Derechos Sociales, no. 2, 2019, p. 323.

${ }^{87}$ LÓPEZ AHUMADA, Eduardo, "La defensa del modelo social de gobernanza del trabajo en el contexto de la globalización económica", Documentos de Trabajo IELAT, nº 146, 2021, p. 16.

${ }^{88}$ BUCKINGHAM, Sophie et alii: Precarious work from a gender and intersectionality perspective, and ways to combat it. cit., p. 60.
} 
ÁLVAREZ CUESTA, Henar, La precariedad en el sector del arte: un estatuto del artista como propuesta de solución. Albacete: Bomarzo, 2019.

ÁLVAREZ CUESTA, Henar, "El futuro del trabajo después de la pandemia y los empleos del futuro", Gaceta Sindical, nº. 35, 2020.

BUCKINGHAM, Sophie et alii: Precarious work from a gender and intersectionality perspective, and ways to combat it. European Unión, 2020.

CARRASCO, Cristina; BORDERÍAS, Cristina y TORNS, Teresa, "El trabajo de cuidado: antecedentes históricos y debates actuales", Revista de Economía Crítica, no ${ }^{\circ}$ 13, 2012.

CORDERO GORDILLO, Vanesa, La relación laboral especial del servicio del hogar familiar. Real Decreto 1620/2011, de 14 de noviembre. Valencia: Tirant lo Blanch, 2014.

CRUZ VILLALÓN, Jesús, "El concepto de trabajador subordinado frente a las nuevas formas de empleo", Derecho Social, nª 83, 2019.

DE LA VILLA GIL, Luis Enrique, "Do ut facias: entorno a los estímulos de la contratación laboral", Revista de la Facultad de Derecho de la Universidad Complutense de Madrid, $\mathrm{n}^{\mathrm{a}}$. 23, 1999.

DE LA VILLA GIL, Luis Enrique, "Contratación temporal", en Unificación de doctrina del Tribunal Supremo en materia laboral y procesal laboral. Estudios en homenaje al Profesor Doctor Efrén Borrajo Dacruz. Valencia: Tirant lo Blanch, 1999.

ESCUDERO RODRÍGUEZ, Ricardo, "Empleo en el sector de la dependencia", Documentación Laboral, $\mathrm{n}^{\mathrm{a}}$. 102, 2014.

ESTEVE SEGARRA, Amparo, "Criterios para la determinación de actividades desarrolladas por empresas multiservicios que contarían con un convenio sectorial de referencia”, en Congreso Nacional de la AEDTSS. Madrid: Iustel, 2018.

FERNÁNDEZ GONZÁLEZ, Cristina, "El papel de la inspección de trabajo y seguridad social en el control del cumplimiento de la normativa aplicable", Revista Lex Social: Revista de Derechos Sociales, $\mathrm{n}^{\circ} .2,2019$.

GARCÍA TESTAL, Elena, "La extinción del contrato de trabajo de los trabajadores domésticos en España: un régimen jurídico injustificadamente diferenciado", Revista Lex Social: Revista de Derechos Sociales, $\mathrm{n}^{\circ} .2,2019$.

GARCÍA-PERROTE ESCARTÍN, Ignacio, "La reforma del artículo 42 del Estatuto de los Trabajadores", Iuslabor, n'. 1, 2019.

GIL Y GIL, José Luis, "Concepto de trabajo decente", Relaciones Laborales, $\mathrm{n}^{\circ}$. 15-16, 2012.

GIL Y GIL, José Luis, “Trabajo decente y reformas laborales”, Revista Derecho Social y Empresa, no. 7, 2017. 
GIL PÉREZ, María Encarnación: “Cuidadores o profesionales y derecho a la incapacidad permanente. Problemas que se plantean”, Revista de Derecho Social, nº 64, 2013.

GONZÁLEZ CALVO, Mercedes, "Presentación”, en La negociación colectiva en las empresas multiservicios. Un balance crítico. Madrid: Fundación $1^{\circ}$ Mayo/Lefebvre el Derecho, 2018.

GONZÁLEZ DEL REY, Ignacio, El contrato de trabajo a tiempo parcial. Pamplona: Aranzadi, 1998.

LAHERA FORTEZA, Jesús, Los contratos temporales en la unificación de doctrina. Madrid: La Ley, 2001.

LÓPEZ AHUMADA, Eduardo, "La defensa del modelo social de gobernanza del trabajo en el contexto de la globalización económica”, Documentos de Trabajo IELAT, $\mathrm{n}^{\circ}$. 146, 2021.

LÓPEZ ANIORTE, M Mal Carmen y FERRANDO GARCÍA, Francisca, "Precariedad y desprotección social del trabajo de limpieza y cuidados ante la situación de crisis sanitaria provocada por la Covid-19”, Revista Internacional y Comparada de relaciones laborales y derecho del empleo, vol. 9, $\mathrm{n}^{\circ} .1,2021$.

LÓPEZ BALAGUER, Mercedes, "Trabajo precario y empresas multiservicios: una propuesta de solución legal”, Revista Jurídica de los Derechos Sociales Lex Social, no. 1, Vol. 9, 2019.

MARTÍN VALVERDE, Antonio, "El discreto retorno del contrato de arrendamiento de servicios", en Cuestiones actuales de Derecho del Trabajo. Estudios ofrecidos por los catedráticos españoles de Derecho del Trabajo al Prof. Manuel Alonso Olea. Madrid: MTSS, 1990.

MARTÍNEZ MORENO, Carolina, Brecha salarial de género y discriminación distributiva: causas y vías para combatirlas. Madrid: Bomarzo, 2019.

MERINO SEGOVIA, Amparo, "La problemática legitimación de las representaciones sociales para negociar y suscribir convenios colectivos en las empresas multiservicios", en La negociación colectiva como instrumento de gestión del cambio. Madrid: Cinca, 2017.

MERINO SENOVILLA, Henar, "El trabajo a tiempo parcial: La nueva delimitación y las líneas fundamentales de su contenido", Revista de Derecho Social, no. 5, 1999.

MOLERO MARAÑÓN, M $M^{\text {a }}$ Luisa, "Las trabajadoras del cuidado: por un futuro del trabajo decente", Revista de Derecho Social, $\mathrm{n}^{\mathrm{a}}$. 89, 2020.

MONEREO PÉREZ, José Luis, "El Derecho del Trabajo en el umbral del siglo XXI: la nueva fase del Derecho del Trabajo", Lan Harremanak, na. 2, 2000.

MONEREO PÉREZ, José Luis, "Evolución y futuro del Derecho del Trabajo: el proceso de racionalización jurídica de la 'cuestión social"”, Relaciones Laborales, na . 15-16, 2001. 
MONEREO PÉREZ, José Luis, "La garantía de los derechos de los trabajadores en la subcontratación empresarial", Derecho de las Relaciones Laborales, vol. 2, 2016.

NIETO ROJAS, Patricia, "La respuesta de la negociación colectiva sectorial a las empresas multiservicios", Información Laboral, nº. 7, 2017.

NIETO ROJAS, Patricia, "La protección de los trabajadores de las empresas multiservicios. Propuestas legales, convencionales y judiciales", Revista Internacional y Comparada de Relaciones Laborales y Derecho del Empleo, Vol. 6, nº 2, 2018.

OJEDA AVILÉS, Antonio y GORELLI HERNÁNDEZ, Juan, Los contratos de trabajo temporales. Madrid: Iustel, 2006.

ORDÓÑEZ PASCUA, Natalia y GONZÁLEZ VIDALES, Cristina, “Los vacíos públicos y privados para asumir la tarea de cuidados familiares. la difícil conciliación en el mundo rural. economía social", en La economía social como palanca para la sostenibilidad en los territorios rurales. Valencia: Tirant lo Blanch, 2021.

QUINTERO LIMA, Ma. Gema, "El trabajo de servicio domestico como una realidad jurídica inevitable", Revista Lex Social: Revista de Derechos Sociales, nº. 2, 2019.

POQUET CATALÁ, Raquel, “Covid-19, crisis sanitaria, económica y laboral: ¿hacia un trabajo decente en el trabajo doméstico?", Revista Internacional y Comparada de relaciones laborales y derecho del empleo, vol. 9, nº 1, 2021.

RODRÍGUEZ ESCANCIANO, Susana, "La crisis en la identidad del modelo 'clásico' de contrato de trabajo: la incidencia del paro y la precariedad", La Ley, n'. 4, 2002.

RODRÍGUEZ ESCANCIANO, Susana, "Dificultades de los servicios sociales en las zonas rurales con especial atención a las personas de edad avanzada", en La economía social como palanca para la sostenibilidad en los territorios rurales. Valencia: Tirant lo Blanch, 2021.

RODRÍGUEZ ESCANCIANO, Susana y ÁLVAREZ CUESTA, Henar, Trabajo autónomo y trabajo por cuenta ajena: nuevas formas de precariedad laboral. Albacete: Bomarzo, 2019.

RODRÍGUEZ RODRÍGUEZ, Emma, "De la conciliación a la corresponsabilidad en el tiempo de trabajo: un cambio de paradigma imprescindible para conseguir el trabajo decente", Revista Lex Social: Revista de Derechos Sociales, nº. 1, 2021.

ROJO TORRECILLA, Eduardo, "El trabajo decente en normas y documentos de la OIT", en Congreso Interuniversitario OIT sobre el futuro del trabajo. Madrid: Ministerio de Trabajo y Economía Social/OIT, 2020.

SALDAÑA VALDERAS, Eva, La discriminación retributiva por razón de género. Sevilla: Mergablum, 2004.

SANZ SÁEZ, Concepción, La protección social de las empleadas de hogar, Albacete: Bomarzo, 2017. 
SANZ SÁEZ, Concepción, "Profesionalización efectiva del servicio doméstico. un trabajo pendiente”, Revista Lex Social: Revista de Derechos Sociales, nº. 2, 2019.

SELMA PENALVA, Alejandra y LUJÁN ALCARAZ, José, "La reforma del régimen especial de la Seguridad Social de los trabajadores empleados de hogar", Foro de Seguridad Social, nº. 20, 2008.

SERVAIS, Jean Michel, International labour market Law. La Haya: Kluwer, 2005.

VICENTE PALACIO, Aránzazu, Empresas multiservicios y precarización del empleo. El trabajador subcedido. Barcelona: Atelier, 2016.

VICENTE PALACIO, Aránzazu, "Empresas multiservicios y precarización en el empleo", Gaceta Sindical, nº. 29, 2017.

\section{Anexo}

EUROPEAN INSTITUTE FOR GENDER EQUALITY, EIGE, Gender inequalities in care and consequences for the labour market, Luxemburgo: Publications Office of the European Union, 2021.

IMSERSO, Datos sobre cuidadores no profesionales a 31 de diciembre de 2020, 2020, https://www.imserso.es/imserso_01/documentacion/estadisticas/info_d/estadisticas/est_i nf/datos_estadisticos_saad/index.htm.

OBSERVATORIO ESTATAL DE LA DEPENDENCIA, $X X$ Dictamen del Observatorio. Madrid: Asociación Estatal de Directoras y Gerentes en Servicios Sociales), 2020, https://dependencia.info/imagenes/xx-dictamen-observatoriodependencia.pdf.

OIT, El trabajo de cuidados y los trabajadores del cuidado para un futuro con trabajo decente. Ginebra: OIT, 2018. 